Supporting Information

\title{
Study on Bacterial Anti-adhesiveness of Stiffness and Thickness Tunable Cross-linked Phospholipid Copolymer Thin-film
}

Zhou Lü, Evan A. Q. Mondarte ${ }^{2}$, Kasinan Suthiwanich ${ }^{2}$, Tomohiro Hayashi ${ }^{2}, 3$, Tsukuru Masuda ${ }^{1}$, Norifumi Isu', and Madoka Takai ${ }^{*}$

${ }^{1}$ Department of Bioengineering, School of Engineering, The University of Tokyo, 7-3-

1 Hongo, Bunkyo-ku, 113-8656, Tokyo, Japan

${ }^{2}$ Department of Materials Science and Engineering, School of Materials and Chemical Technology, Tokyo Institute of Technology, 4259 Nagatsuta-cho, Midori-ku, 2268502, Yokohama, Kanagawa Japan

${ }^{3}$ JST-PRESTO, 4-1-8 Hon-cho, Kawaguchi, Saitama 332-0012, JAPAN

${ }^{4}$ LIXIL Corporation, 2-1-1 Ojima, Koto-ku, 136-8535, Tokyo, Japan

*E-mail: takai@bis.t.u-tokyo.ac.jp 


\section{S1 ${ }^{1}$ HMR characterization of PMMMSi}

The composition of the obtained copolymer was characterized by ${ }^{1} \mathrm{H}$ NMR measurement. The ${ }^{1}$ NMR spectrum are shown in Figure S1.
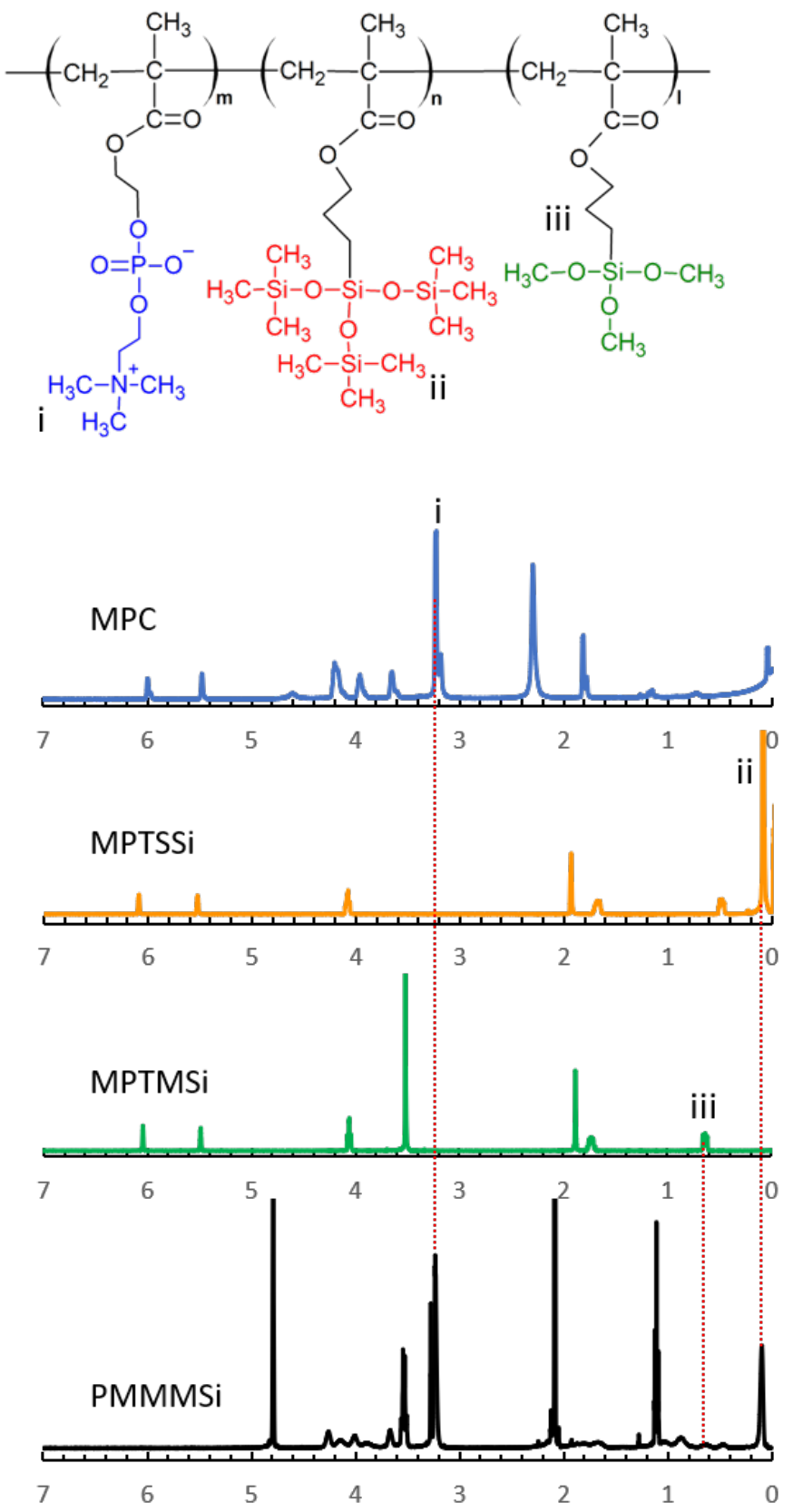

Figure S1 (Top) Chemical structure of PMMMSi. (Bottom) ${ }^{1} \mathrm{H}$ NMR spectra of monomers (MPC, MPTSSi, and MPTMSi) and the obtained PMMMSi. 


\section{S2 Chemical composition characterization by XPS}

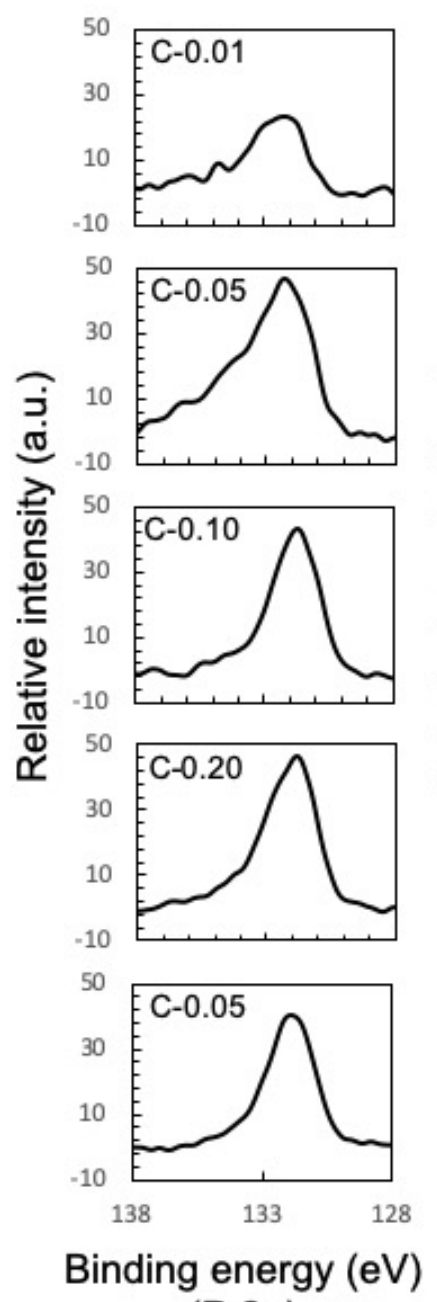

(P 2p)

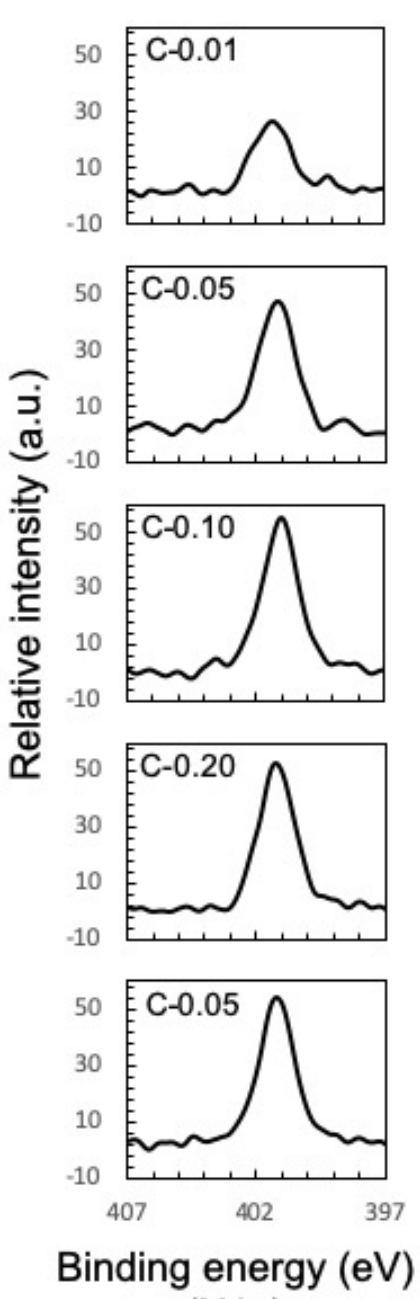

(N1s)

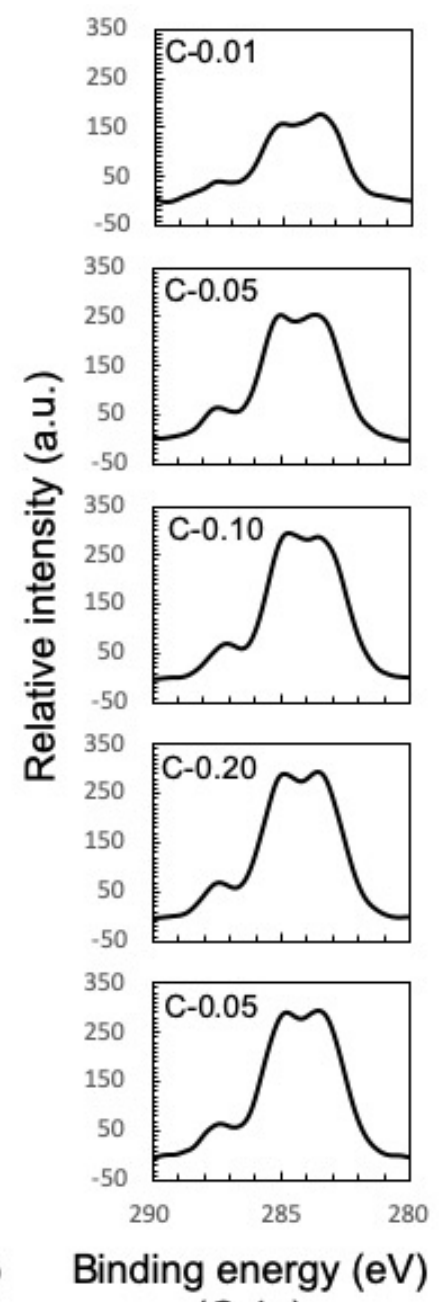

(C 1s)

Figure S2 XPS spectra of each PMMMSi coating surface

\section{S3 Calculation of the overlap concentration}

According to the Flory's theory ${ }^{\mathrm{S} 1}$, the overlap volume fraction $\left(\varphi^{*}\right)$ is calculated by the following equation:

$$
\varphi *=N^{1-3 v}
$$

where $N$ is the degree of the polymerization. The parameters used for the following calculation is summarized in Table S1. The $v$ value for real chains in a good solvent is $3 / 5$. On the basis of the number-averaged molecular weight determined by GPC measurement and the averaged molar mass of the unit (309.9), the $N$ value was calculated to be 549 . Thus, the overlap volume 
fraction, $\varphi^{*}$, is ca. 0.006436 .

To compare with our experimental condition, the calculated value (volume fraction) is converted into the weight fraction by using the mass density. Here, the averaged-mass density of the polymer and mass density of solvent (methanol) are $1.20 \mathrm{~g} / \mathrm{cm}^{3}$ and $0.792 \mathrm{~g} / \mathrm{cm}^{3}$, respectively. Thus, the overlap concentration was estimated to be ca. $0.97 \mathrm{wt} \%$.

The overlap of polymer molecules leaded to the increase of viscosity of the solution as shown in Figure S3.

Table S1 The parameters used for the calculation of the overlap concentration

\begin{tabular}{cccc}
\hline Monomer unit & $\begin{array}{c}\text { Molar mass of the } \\
\text { unit }(\mathrm{g} / \mathrm{mol})\end{array}$ & $\begin{array}{c}\text { Contents in the } \\
\left.\text { copolymer }{ }^{\mathrm{a}}\right)\end{array}$ & $\begin{array}{c}\text { Mass density } \\
\left(\mathrm{g} / \mathrm{cm}^{3}\right)\end{array}$ \\
\hline MPC & 295.3 & 0.68 & $1.3^{\mathrm{b})}$ \\
MPTSSi & 422.8 & 0.17 & 0.925 \\
MPTMSi & 248.4 & 0.15 & 1.045 \\
\hline
\end{tabular}

a) Determined by ${ }^{1} \mathrm{H}$ NMR. b) Mass density of PMPC reported in a previous study ${ }^{\mathrm{S} 2}$.

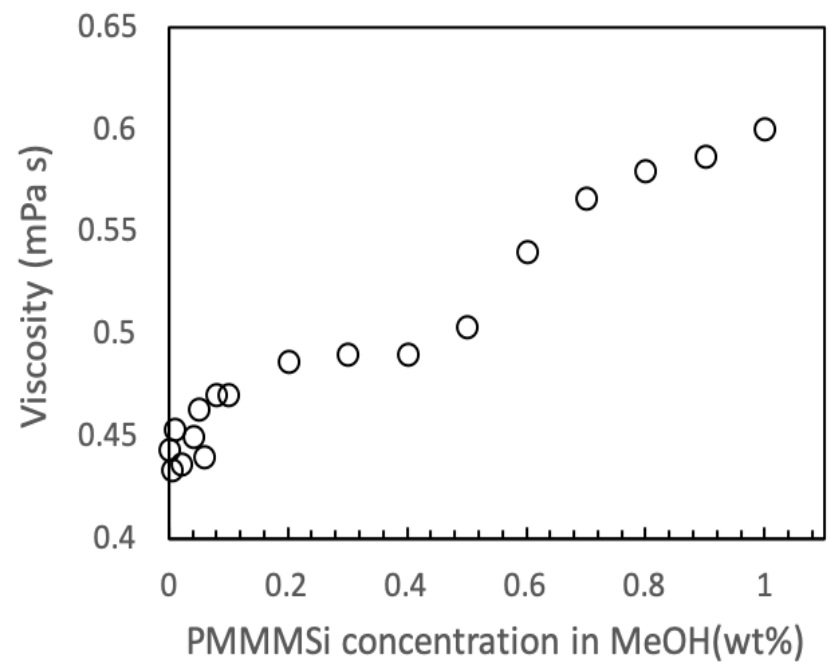

Figure S3 Viscosity of PMMMSi/Methanol solution as a function of the polymer concentration. Measured by a viscometers (VM-10A, SEKONIC Corp.)

\section{S4 Bottom-substrate correction of thin-film modulus}

The effect of substrate below the films can interfere with the conventional evaluations of sample modulus, e.g. Hertz, JKR or DMT models because of the nm-scaled thinness of sample 
films. Recently, many researchers have developed a set of equations to correct the bottomsubstrate effect ${ }^{\mathrm{S} 3-6}$ to which we assumed all sample films, bonded to their substrates, to have 0.5 Poisson ratio. Assuming our AFM tips to be conical with $35^{\circ}$ semi-angle, we employed the approximation equation from $\mathrm{Garcia}^{\mathrm{S} 3}$ as followed;

$$
\begin{aligned}
F=\frac{(8 \tan \theta)}{3 \pi} E & \delta^{2}\left[1+0.721 \frac{\delta \tan \theta}{h}+0.650\left(\frac{\delta \tan \theta}{h}\right)^{2}+0.491\left(\frac{\delta \tan \theta}{h}\right)^{3}\right. \\
+ & \left.0.225\left(\frac{\delta \tan \theta}{h}\right)^{4}\right]
\end{aligned}
$$

where; $\theta$ is the conical semi-angle $\left(35^{\circ}\right), \delta$ is the indentation, $h$ is the film thickness, and $E$ is the film modulus. The relationship of the film thickness and modulus was shown as Figure

\section{S4}

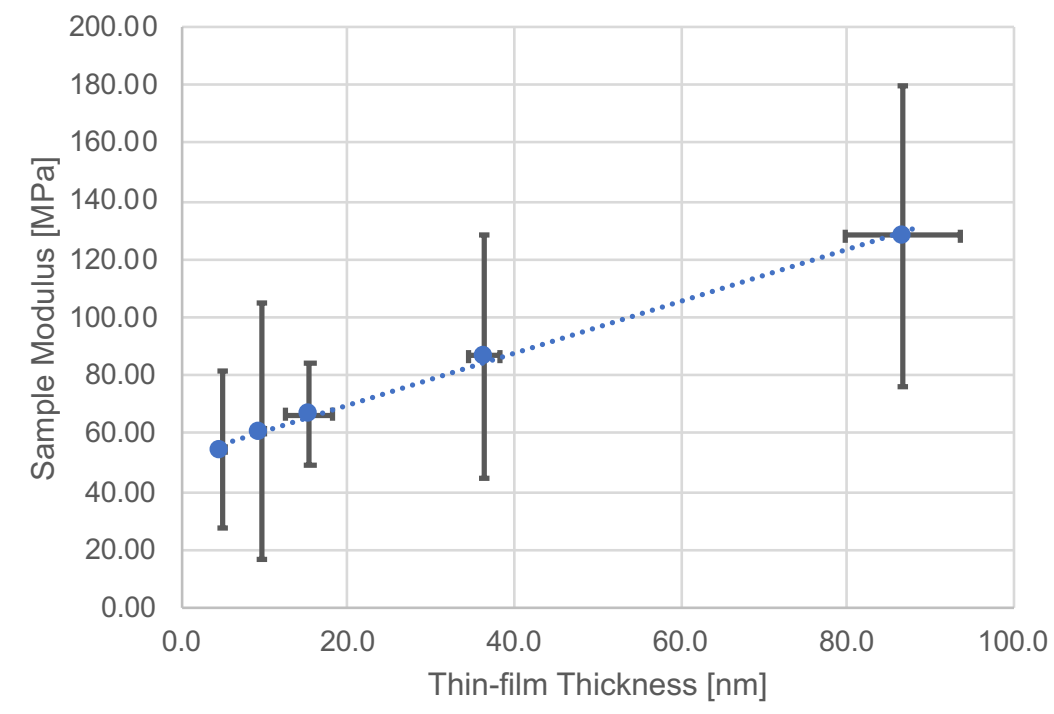

Figure S4 The relationship between sample thickness and modulus. For each sample thickness, eight force-indentation curves were randomly chosen for evaluating the sample modulus with the bottom-substrate correction.

This resulting film modulus can be further converted to the sample modulus (Eq. S3) when considering the tip modulus and Poisson ratio to be $150 \mathrm{GPa}$ and 0.17 , respectively.

$$
\frac{1}{E}=\frac{1-v^{2}}{E_{S}}+\frac{1-v_{i}^{2}}{E_{i}}
$$


Where $v$ is the smaple's Poison ratio, $v_{i}$ is the indenter's Poisson ratio $(0.17), E_{s}$ is the samples's modulus and $\mathrm{E}_{\mathrm{i}}$ is the indenter's modulus $(150 \mathrm{GPa})$

\section{S5 Bacterial culture and density determination}

Staphylococcus aureus (NBRC 13276, Biotechnology Center, National Institute of Technology and evaluation, Japan) and Pseudomonas aeruginosa (JCM14847, Riken Bio Resource Center, Japan) glycerol stock were stored at $-80^{\circ} \mathrm{C}$. Prior to the experiment, the stock bacterial was transferred into $0.5 \mathrm{~mL}$ TSB in a $1.5 \mathrm{~mL}$ microtube through tooth pick dipping, followed by incubation at $37^{\circ} \mathrm{C}$ overnight. The incubated bacterial medium was transferred into $20 \mathrm{~mL}$ fresh TSB (preheated to $37^{\circ} \mathrm{C}$ ) in a $50 \mathrm{~mL}$ microtube and incubated on a $160 \mathrm{rpm}$ rotation shaker at the same temperature for 3 hours until the optical density at $600 \mathrm{~nm}\left(O D_{600}\right.$, WPACO8000, Biochrom Ltd., UK) of the medium reached to approximately 0.5 . We calculated the bacterial density in the medium using the following equation:

$$
\text { Cell density }=8 \times O D_{600} \times 10^{8} \text { cells } / \mathrm{mL}
$$

This medium was diluted with fresh TSB to $10^{7}$ cells $/ \mathrm{mL}$, and this solution was used for bacterial adhesion testing. In the 24-h experimental period, bacteria density was monitored and shown as following graph/

(a)

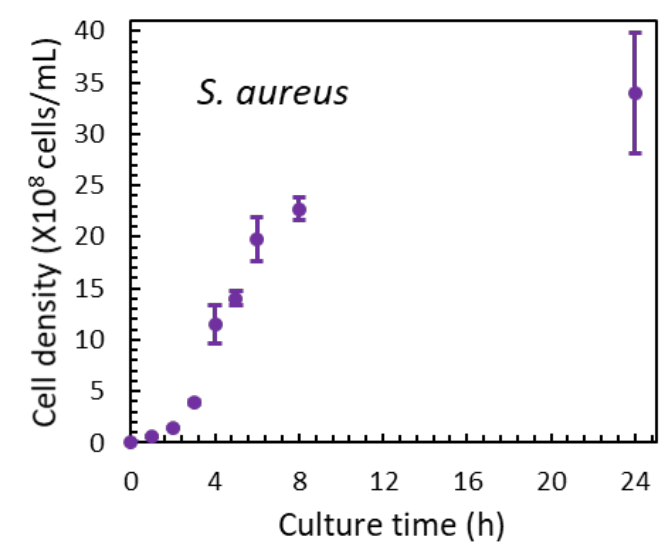

(b)

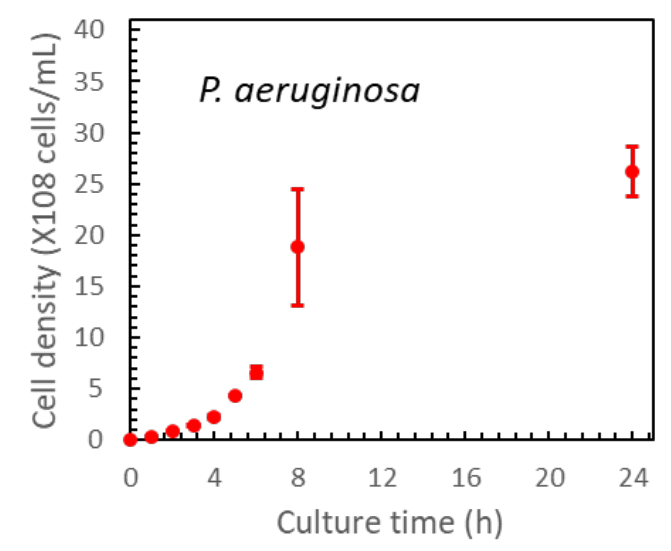

Figure S5 S. aureus (a) and P. aeruginosa (b) growth curve in TSB. 
A nutrient free M9 experimental medium was prepared as an aqueous solution (1 L) containing $17.2 \mathrm{~g} \mathrm{Na}_{2} \mathrm{HPO}_{4}, 3 \mathrm{~g} \mathrm{KH}_{2} \mathrm{PO}_{4}, 1 \mathrm{~g} \mathrm{NH}$ Cl and $0.5 \mathrm{~g} \mathrm{NaCl}$. The TSB medium containing bacteria $\left(O D_{600} \approx 0.5\right)$ was centrifuged $(1900 \mathrm{G}, 5 \mathrm{~min})$ to remove the supernatant, and the microtube was refilled with fresh M9 medium to resuspend the bacteria. Measurement of the $O D_{600}$ value and calculations for the bacterial density were performed according to $E q$. $S 2$. We adjusted the bacterial density to $10^{8}$ cells $/ \mathrm{mL}$ with $\mathrm{M} 9$ medium. Because the bacterial number did not increase in M9 medium, we increased the bacterial density to make sure there were enough bacterial cells for the experiment.

P. aeruginosa cultured in TSB and M9 were observed using SEM as shown in following picture.

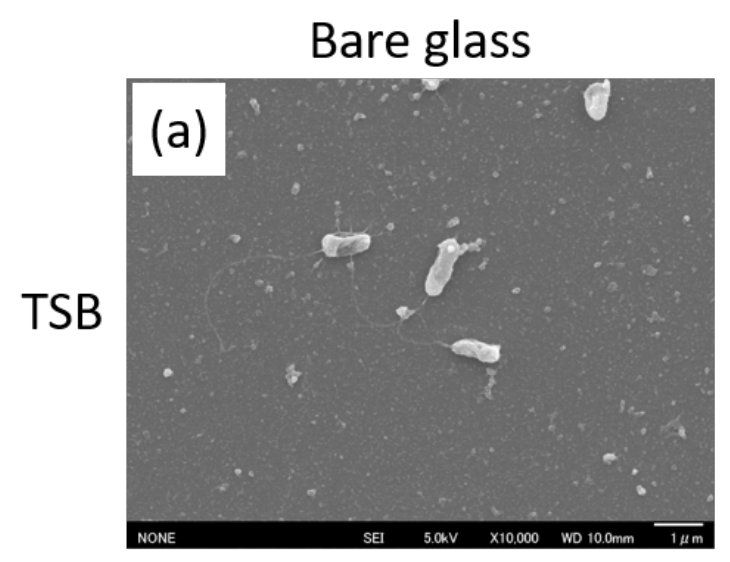

PMMMSi-coated glass
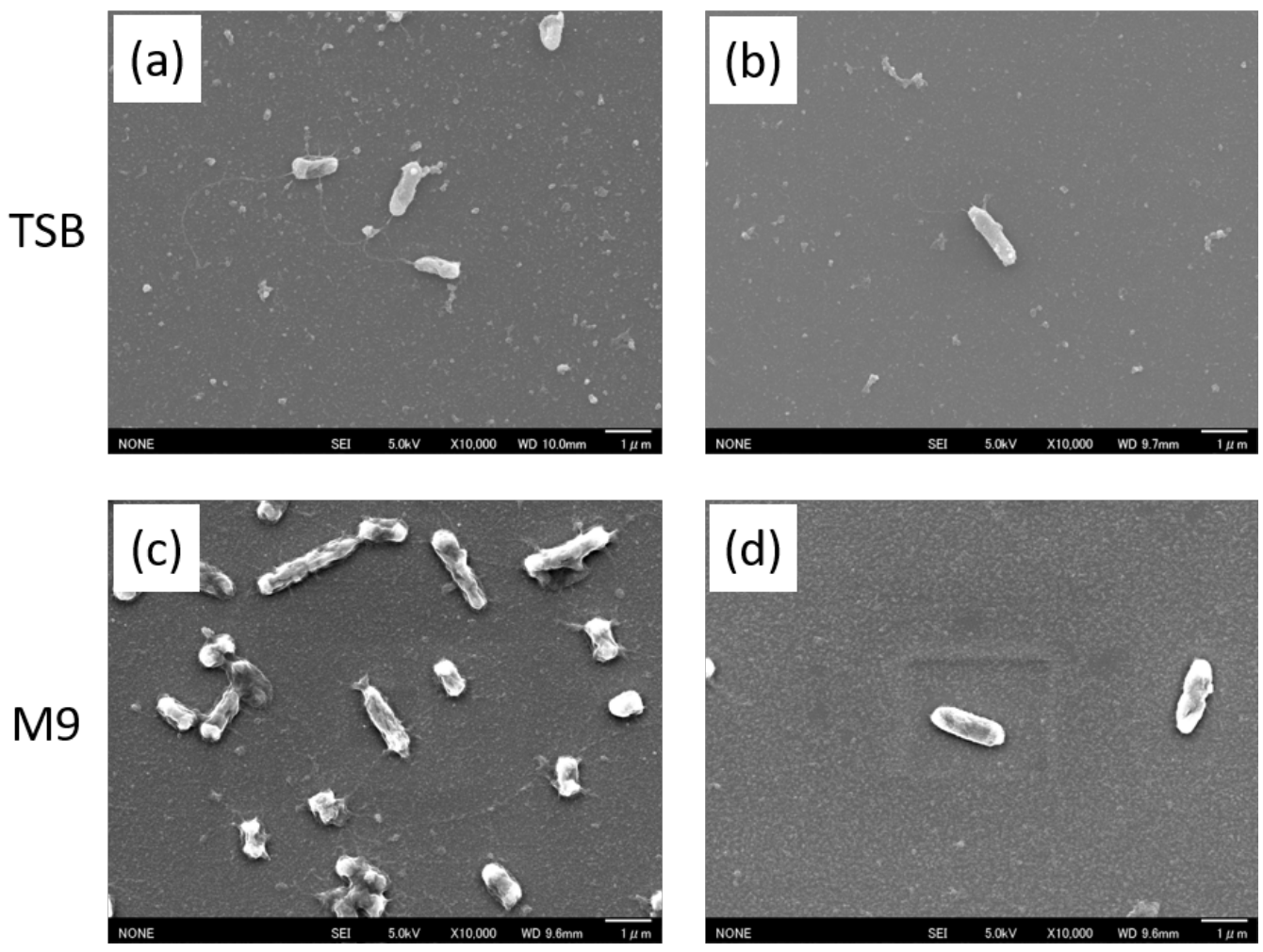

Figure S6 SEM images of $P$. aeruginosa adhered on bare (a, c) or PMMMSi-coated (b, d) glass surfaces when it was incubated in TSB $(a, b)$ or M9 (c, d). Notably, the number of bacterial cells in these images did not represent the statistical amount of the entire surfaces. 


\section{S6 Determination of protein adsorption on PMMMSi films}

The QCM chip, an AT-cut Au-coated quartz crystal with a $\mathrm{SiO}_{2}$ layer on the top (QSensor QSX $303 \mathrm{SiO}_{2}$, Biolin Scientific, Sweden), was used as substrate and performed the similar polymer coating protocol as that on the glass slide. During the coating process, the QCM chip was mounted in an open measurement cell which ensured the coating treatment only perform to the surface of the chip. After coating, the QCM chip was moved to a QCM flow module. PBS was pumped over the chip at a flow rate of $100 \mu \mathrm{L} / \mathrm{min}$ until the system was balanced (about $1 \mathrm{~h}$ was needed). Then the PBS containing $0.1 \mathrm{mg} / \mathrm{mL}$ fibrinogen $(\mathrm{Fg}$ ) was pumped through the chip at the same flow rate for 20 min then the medium was shifted to fresh PBS (Fg free) and kept running for $30 \mathrm{~min}$ to remove the non-bonding protein. The resonance frequency shift was recorded over the third, fifth and seventh overtones. The amount of adsorbed protein was calculated using the following equation.

$$
m_{F g}=-C \Delta f
$$

where $\mathrm{m}_{\mathrm{Fg}}$ is the mass of the adsorbed $\mathrm{Fg}$ on the QCM chip, $\mathrm{C}$ is the sensor constant, $\mathrm{C}=17.7$ $\mathrm{ng} / \mathrm{cm}^{2} \mathrm{~Hz}$, and $\Delta f(f$ in $\mathrm{Hz})$ is the normalized frequency change for each overtone.

Fg adsorption on each sample was shown in following figure.

(a)

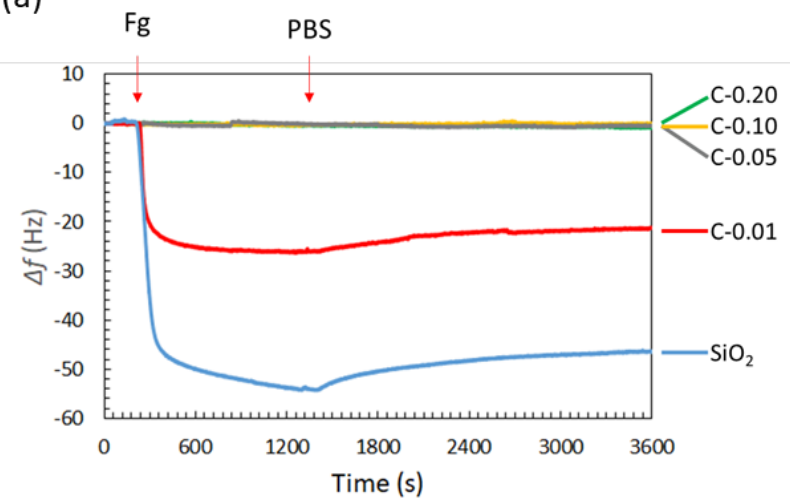

(b)

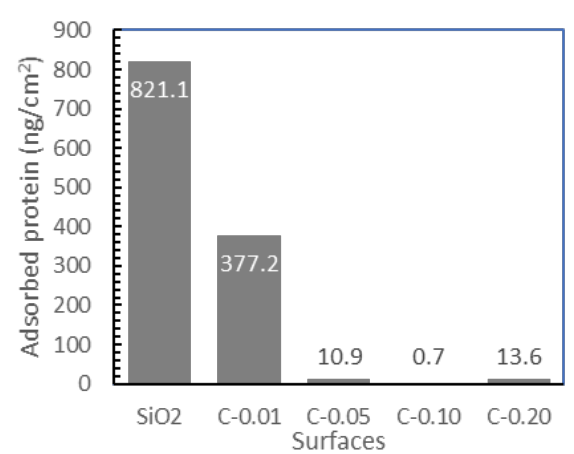

Figure S7 QCM data showing (a) $\Delta f$ and the (b) amount of adsorbed Fg. 


\section{References}

(S1) Bhattacharjee, S. M.; Giacometti, A.; Maritan, A. Flory theory for polymers. J. Phys. Conden.s Matter. 2013, 25, p. 503101.

(S2) Iwata, R.; Suk-In, P. V.; Hoven, P.; Takahara, A.; Akiyoshi, K.; Iwasaki, Y. Control of Nanobiointerfaces Generated from Well-Defined Biomimetic Polymer Brushes for Protein and Cell Manipulations Biomacromolecules 2004, 5, 2308 - 2314.

(S3) Dimitriadis, E. K.; Horkay, F.; Maresca, J.; Kachar, B.; Chadwick, R. S., Determination of Elastic Moduli of Thin Layers of Soft Material Using the Atomic Force Microscope. Biophys. J. 2002, 82, 2798-2810.

(S4) Gavara, N.; Chadwick, R. S., Determination of the elastic moduli of thin samples and adherent cells using conical atomic force microscope tips. Nat. Nanotechnol. 2012, 7, 733-736.

(S5) Garcia, P. D.; Garcia, R., Determination of the Elastic Moduli of a Single Cell Cultured on a Rigid Support by Force Microscopy. Biophys. J. 2018, 114, 2923-2932.

(S6) Managuli, V.; Roy, S., Asymptotical Correction to Bottom Substrate Effect Arising in AFM Indentation of Thin Samples and Adherent Cells Using Conical Tips. Experimental Mechanics 2018, 58, 733-741. 